\title{
Coeliac trunk and common hepatic artery variations in children: an analysis with computed tomography angiography
}

\author{
E. Caliskan, T. Acar, M. Ozturk, Z. Bayramoglu, R. Yılmaz, F. Elbuken, I. Adaletli
}

Department of Paediatric Radiology, Istanbul Faculty of Medicine, Istanbul, Turkey

[Received: 14 January 2018; Accepted: 19 March 2018]

\begin{abstract}
Background: Understanding the coeliac trunk (CeT) and hepatic artery anatomy is important not only in preventing iatrogenic injuries but also in planning surgical procedures in children. Therefore, the aim of this study is to analyse the prevalence of $\mathrm{CeT}$ and common hepatic artery (CHA) variations in the paediatric population. Materials and methods: One hundred and seventy-four children who underwent abdominal multidetector computed tomography (MDCT) angiography, either because of trauma or liver transplantation, were analysed retrospectively. The patterns of CeT, CHA and their variant branches were revealed and compared with previous studies involving adults.
\end{abstract}

Results: A total of 157 (90.2\%) of the 174 patients had normal CeT anatomy, whereas 17 (9.8\%) had variations. Five types of CeT variations were identified according to Song's classification in which 'hepatosplenic trunk + left gastric artery + superior mesenteric artery' was the most prevalent. One hundred-twelve (64.4\%) of the 174 patients had normal CHA anatomy; however, 62 (35.6\%) had variations. Six types of CHA variations were identified according to Michel's and Hiatt's classification. The most common was 'replaced left hepatic artery originating from left gastric artery'.

Conclusions: The prevalences of $\mathrm{CeT}$ and hepatic artery variations are high in children, as they are in older patients. Awareness of these variations is important in terms of avoiding iatrogenic injury and in promoting surgical procedure planning for liver transplantation or abdominal tumour surgery. (Folia Morphol 2018; 77; 4: 670-676)

Key words: coeliac trunk, computed tomography angiography, hepatic artery, variation

\section{INTRODUCTION}

The coeliac trunk (CeT) is the first and most important branch of the abdominal aorta. Characteristically, the common hepatic artery ( $\mathrm{CHA})$, the left gastric artery and the splenic artery are known as the main branches of the CeT. Currently, the segment from the hepatic artery to the branch point of the gastrodu- odenal artery is defined as CHA [5]. The branches of the $\mathrm{CHA}$ arising from the $\mathrm{CeT}$ are described as having normal course when the right hepatic artery and left hepatic artery originate from the proper hepatic artery which supplies the liver, gastroduodenal artery and right gastric artery. In variant anatomy, vessels do not arise from their usual source and present as accesso-

Address for correspondence: E. Caliskan, MD, Department of Paediatric Radiology, Istanbul Faculty of Medicine, Istanbul, Turkey, Turgut Ozal Street, Fatih, Istanbul, Turkey, tel: +90 53038897 24, ORCID:0000-0001-9869-1396, fax:+90 21241420 00, e-mail: eminecaliskanrad@gmail.com 
ry or replaced vessels $[6,7]$. The importance of CeT and CHA is regarded as their vascularisation which is crucial for interventional and surgical procedures like liver transplantation and surgical preoperative planning $[8,15]$. It is critical to be aware of not only normal anatomy but also its variants to prevent iatrogenic injuries and to plan surgical techniques, especially in children because of long life expectancy.

Anatomical variations of the CeT and CHA which have various classifications have been documented and classified several times in the available literature with MDCT angiography, digital subtraction angiography or cadaveric dissections [17, 19, 23]. CeT and CHA with normal anatomy were seen in most of the previous studies; however, some authors reported a number of variations. The main variants of $\mathrm{CeT}$ and CHA anatomy were introduced by Michel [16], Hiatt et al. [10], and Lipshutz [14] and reinvestigated in recent years by Song et al. [25], lezzi et al. [12], and Natsume et al. [18] in adults. However, according to the best of our knowledge a relatively scarce number of articles are currently available covering the paediatric population. Therefore, the aim of this study is to analyse the prevalence of $\mathrm{CeT}$ and $\mathrm{CHA}$ variations in the paediatric population who underwent MDCT angiography and compare results with studies involving adults.

\section{MATERIALS AND METHODS}

\section{Patients}

Two hundred children who underwent abdominal MDCT angiography because of trauma or liver transplantation from June 2013 to April 2017 were retrospectively evaluated. Twenty-six cases were excluded from the study due to motion artefacts or traumatic vascular injury. Finally, $174 \mathrm{MDCT}$ angiographies of 174 children were evaluated by two radiologists with consensus. Patients were divided into two subgroups as normal and variant anatomy. The pattern of CeT, $\mathrm{CHA}$ and their branches were analysed and compared with previous studies involving adults. During detailed analysis, as proposed by Michel [16], Hiatt et al. [10], and Song et al. [25], Tables 1 and 2 were used to describe and evaluate these arteries.

The study was conducted with ethics approval from the Ethics Committee of Istanbul University Faculty of Medicine (number: 2017/1050). Each parent received a detailed explanation of the MDCT angiography examination and intravenous contrast material which were indicated because of the elevated liver enzymes or high energy trauma and gave written informed consent prior to examination. We presented the information and images of the patients fully anonymous.

\section{Ethical approval}

The institutional review board approved the study and waived the need for patient consent.

\section{MDCT angiography examination}

All MDCT angiography examinations were performed by a 64-slice CT scanner (Aquillon 64; Toshiba Medical Systems). The imaging data were acquired during an intravenous injection of 1.5 to $2 \mathrm{~mL} / \mathrm{kg}$ of the contrast agent at a rate of 1 to $3 \mathrm{~mL} / \mathrm{s}$ for children, but the contrast media was manually injected for infants. Saline solution of 4 to $15 \mathrm{~mL}$ followed the contrast material. The voltage and tube current were adjusted to the patient's weight as follows: $80 \mathrm{kV}$ was used for patients weighing $<30 \mathrm{~kg}$, and $100 \mathrm{kV}$ for those weighing 30-60 kg; tube current was $10 \mathrm{~mA} / \mathrm{kg}$ for patients weighing $<9 \mathrm{~kg}$, and $5 \mathrm{~mA}$ for each additional $\mathrm{kg}$. Section thickness was $0.5 \mathrm{~mm}$, reconstruction interval was $0.3 \mathrm{~mm}$ and the scan revolution time was $0.4 \mathrm{~s}$. All MDCT angiography data were transferred to a workstation (Osirix MD 7 for MAC) in order to evaluate vascular anatomy. Basically, axial and sagittal-coronal reformat images were analysed for each case. In appropriate minority of the cases, three-dimensional post-processing such as multiplanar image reformatting (MPR) and maximum intensity projections (MIP) were also performed where possible.

\section{Statistical analysis}

Descriptive statistics regarding the age and gender of the patients were presented with minimum, maximum, mean and standard deviation via SPSS 22.0 (SAS version 9.2; SAS Institute Inc., Cary, NC, USA). The distributions of the variations were provided as frequencies. All data were managed, processed, and compiled in Microsoft Office Excel. Mann-Whitney $\mathrm{U}$ test was used to compare the distribution of $\mathrm{CeT}$ and $\mathrm{CHA}$ variations in males and females.

\section{RESULTS}

One hundred seventy-four cases (99 males, 75 females; aged between 5 months and 16 years; mean 7 years \pm 2 months) were enrolled in the study. There was no significant difference between males and females in terms of $\mathrm{CeT}$ and $\mathrm{CHA}$ variations (35.3\%, $35.9 \%$, respectively). 
Table 1. Hepatic artery variations: the Michel's and Hiatt's classification [10, 16]

\begin{tabular}{lll}
\hline Michel's classification & Hiatt's classification & Hepatic artery variations \\
\hline Type I & Type I & Normal anatomy (classical trifurcation) \\
Type II & Type II & The replaced LHA originating from LGA \\
Type III & Type III & The replaced RHA originating from the SMA \\
Type IV & Type IV & Co-existence of Types II and III \\
Type V & Type II & The accessory LHA originating from LGA \\
Type VI & Type III & The accessory RHA originating from SMA \\
Type VII & Type IV & The accessory LHA originating from LGA + the accessory RHA originating from SMA \\
Type VIII & Type IV & The accessory LHA originating from LGA + the replaced RHA originating from SMA \\
Type IX & Type V & The CHA originating from SMA \\
Type X & NOD & RHA and LHA originating from the LGA \\
NOD & Type VI & The CHA directly originating from the aorta \\
\hline
\end{tabular}

CHA — common hepatic artery; LGA — left gastric artery; LHA — left hepatic artery; NOD — not otherwise described in the literature; RHA — right hepatic artery; SMA — superior mesenteric artery

Table 2. Coeliac trunk variations in 5002 patients by Song et al. [25]

\begin{tabular}{lc}
\hline Coeliac trunk anatomy type & Number of patients (n= 5002) \\
\hline Normal anatomy & $4457(89.1 \%)$ \\
Variant anatomy: & $482(9.6 \%)$ \\
Hepatosplenic trunk + left gastric artery + superior mesenteric artery & $221(4.42 \%)$ \\
Hepatomesenteric trunk + gastrosplenic trunk & $132(2.64 \%)$ \\
Gastromesenteric trunk & $53(1.06 \%)$ \\
Hepatosplenomesenteric trunk + left gastric artery & $34(0.68 \%)$ \\
Hepatomesenteric trunk + left gastric artery + splenic artery & $12(0.24 \%)$ \\
Common hepatic artery + gastrosplenic trunk + superior mesenteric artery & $11(0.22 \%)$ \\
Hepatogastric trunk + splenomesenteric trunk & $8(0.16 \%)$ \\
Common hepatic artery + left gastric artery + splenic artery + superior mesenteric artery & $5(0.10 \%)$ \\
Common hepatic artery + gastrosplenomesenteric trunk & $3(0.06 \%)$ \\
Common hepatic artery + left gastric artery + splenomesenteric trunk & $1(0.02 \%)$ \\
Hepatogastric trunk + splenic artery + superior mesenteric artery & $1(0.02 \%)$ \\
Hepatosplenic trunk + gastromesenteric trunk & $1(0.02 \%)$ \\
Hepatogastromesenteric trunk + splenic artery & 0 \\
Common hepatic artery + gastromesenteric trunk + splenic artery & 0 \\
\hline
\end{tabular}

\section{Coeliac trunk variations}

A total of 157 (90.2\%) of the 174 patients had normal CeT anatomy with hepatogastrosplenic trunk separating from the aorta, which was called trifurcation, and 17 (9.8\%) had variant anatomy. In our study, 5 of the 15 possible CeT variations were identified according to the classification by Song et al. [25] (Table 3). 'Hepatosplenic trunk + left gastric artery + superior mesenteric artery' was seen in 7 (4\%) patients, 'hepatomesenteric trunk + gastrosplenomesenteric trunk' was seen in $5(2.8 \%)$ patients, 'coeliacomesenteric trunk' was seen in $3(1.8 \%)$ patients, 'hepat- osplenomesenteric trunk + left gastric artery' was seen in $1(0.6 \%)$ patient, and 'hepatogastric trunk + splenomesenteric trunk' was seen in $1(0.6 \%)$ patient.

\section{Common hepatic artery variations}

A total of 112 (64.4\%) of the 174 patients had normal CHA anatomy originating from the CeT and 62 (35.6\%) had variant anatomy. In our study, 6 of the 10 possible $\mathrm{CHA}$ variations were identified according to the classification by Michel [16] and Hiatt et al. [10] (Table 4). 'Replaced left hepatic artery originating from left gastric artery' was seen in 21 (12.0\%) 
Table 3. Results in the current study (according to abbreviations of Song et al. [25])

\begin{tabular}{lc}
\hline Coeliac trunk anatomy type & Number of patients (n = 174) \\
\hline Normal anatomy & $157(90.2 \%)$ \\
Variant anatomy & $17(9.8 \%)$ \\
$\begin{array}{l}\text { Hepatosplenic trunk + left gastric } \\
\text { artery + superior mesenteric artery }\end{array}$ & $7(4 \%)$ \\
$\begin{array}{l}\text { Hepatomesenteric trunk } \\
+ \text { gastrosplenic trunk }\end{array}$ & $5(2.8 \%)$ \\
$\begin{array}{l}\text { Gastromesenteric trunk } \\
\text { Hepatosplenomesenteric trunk } \\
+ \text { left gastric artery }\end{array}$ & $3(1.8 \%)$ \\
$\begin{array}{l}\text { Hepatogastric trunk } \\
+ \text { splenomesenteric trunk }\end{array}$ & $1(0.6 \%)$ \\
\hline
\end{tabular}

Table 4. Results in the current study (according to the classification of Michel et al. [16] and Hiatt et al. [10])

\begin{tabular}{lc}
\hline $\begin{array}{l}\text { Common hepatic artery } \\
\text { anatomy type }\end{array}$ & $\begin{array}{c}\text { Number of patients } \\
\text { ( } \mathbf{n}=174)\end{array}$ \\
\hline Normal anatomy & $112(64.4 \%)$ \\
Variant anatomy: & $62(35.6 \%)$ \\
The replaced LHA originating from & $21(12.0 \%)$ \\
LGA (type II) & \\
The replaced RHA originating from \\
the SMA (type III) \\
$\begin{array}{l}\text { The accessory LHA originating from } \\
\text { LGA (type V or type II) }\end{array}$ \\
$\begin{array}{l}\text { The accessory RHA originating from } \\
\text { SMA (type VI or type III) }\end{array}$ \\
$\begin{array}{l}\text { The CHA originating from SMA } \\
\text { (type IX or type V) }\end{array}$ \\
$\begin{array}{l}\text { The CHA directly originating from } \\
\text { the aorta (NOD or type VI) }\end{array}$ \\
\hline
\end{tabular}

CHA — common hepatic artery; LGA — left gastric artery; LHA — left hepatic artery; RHA — right hepatic artery; SMA — superior mesenteric artery

patients (Fig. 1), 'Replaced right hepatic artery originating from the superior mesenteric artery' was seen in $18(10.3 \%)$ patients (Fig. 2), 'Accessory left hepatic artery originating from left gastric artery' was seen in $14(8.0 \%)$ patients, 'Accessory right hepatic artery originating from superior mesenteric artery' was seen in $7(4 \%)$ patients, 'CHA originating from superior mesenteric artery' was seen in 1 (0.6\%) patient (Fig. 3), and 'CHA directly originating from the aorta' was seen in $1(0.6 \%)$ patient (Fig. 4).

\section{DISCUSSION}

The present study demonstrates that vascularity of $\mathrm{CeT}$ and $\mathrm{CHA}$ have a high variation rate. Classical arterial anatomy is that the $\mathrm{CeT}$ originates from the

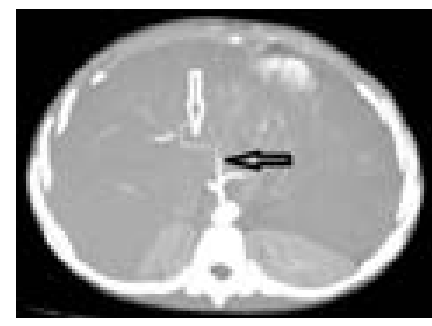

Figure 1. Axial computed tomography scan illustrates replaced left hepatic artery (white arrow) originating from left gastric artery (black arrow).

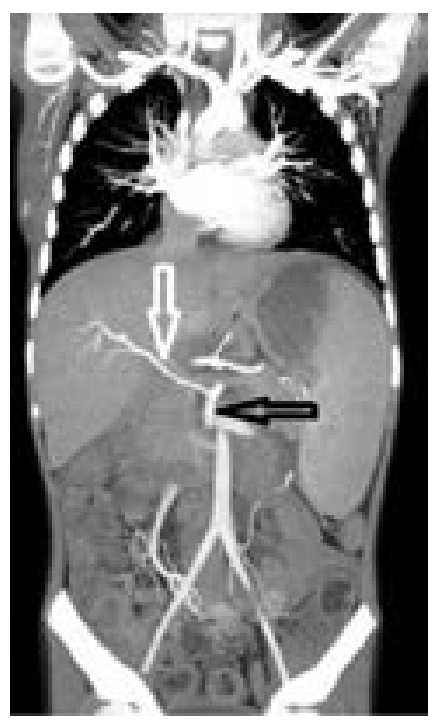

Figure 2. Coronal maximum intensity projection image shows replaced right hepatic artery (white arrow) originating from the superior mesenteric artery (black arrow).

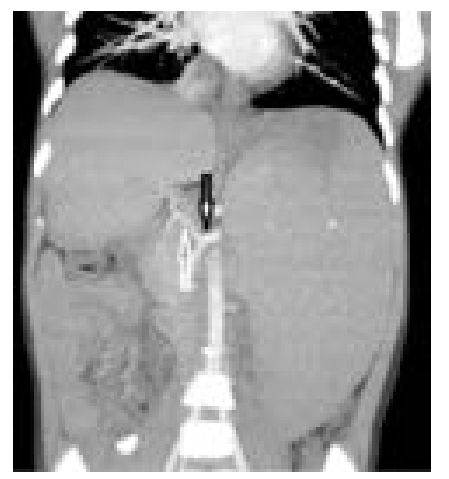

Figure 3. Coronal maximum intensity projection image shows common hepatic artery (white arrow) originating from superior mesenteric artery (black arrow).

abdominal aorta at the level of the T12 thoracic vertebra and divides into three main branches as CHA, splenic artery and left gastric artery [26]. The vascularisation of the liver is provided by the $\mathrm{CHA}$ originating 


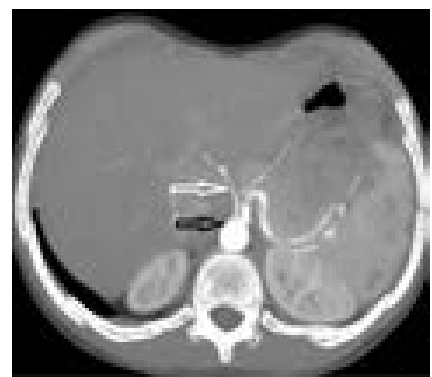

Figure 4. Axial maximum intensity projection image shows common hepatic artery (white arrow) directly originating from the aorta (black arrow).

Table 5. Normal and variant pattern of the coeliac trunk

\begin{tabular}{lcccc}
\hline Study & Race & $\begin{array}{c}\text { Number } \\
\text { of the } \\
\text { study }\end{array}$ & $\begin{array}{c}\text { Normal } \\
\text { pattern }\end{array}$ & $\begin{array}{l}\text { Variant } \\
\text { pattern }\end{array}$ \\
\hline Current study (children) & Turkey & 174 & $90.2 \%$ & $9.8 \%$ \\
Chen et al. [4] (adults) & Japanese & 974 & $89.8 \%$ & $10.2 \%$ \\
Song et al. [25] (adults) & Korean & 5002 & $89.1 \%$ & $10.9 \%$ \\
Prakash et al. [22] (adults) & Indian & 50 & $86 \%$ & $14 \%$ \\
lezzi et al. [12] (adults) & Caucasian & 524 & $87.6 \%$ & $12.4 \%$ \\
\hline
\end{tabular}

Table 6. Normal and variant pattern of the hepatic artery

\begin{tabular}{|c|c|c|c|c|}
\hline Study & Country & $\begin{array}{c}\text { Number } \\
\text { of the } \\
\text { study }\end{array}$ & $\begin{array}{l}\text { Normal } \\
\text { pattern }\end{array}$ & $\begin{array}{l}\text { Variant } \\
\text { pattern }\end{array}$ \\
\hline Current study (children) & Turkey & 174 & $64.4 \%$ & $35.6 \%$ \\
\hline Gumus et al. [9] (adults) & Turkey & 820 & $76.8 \%$ & $33.2 \%$ \\
\hline $\begin{array}{l}\text { Bertevello et al. [1] } \\
\text { (adults) }\end{array}$ & Brazil & 60 & $68.3 \%$ & $31.7 \%$ \\
\hline Song et al. [25] (adults) & Korean & 5002 & $58 \%$ & $42 \%$ \\
\hline Sureka et al. [27] (adults) & India & 600 & $79.6 \%$ & $20.4 \%$ \\
\hline $\begin{array}{l}\text { Tharangarajah et al. [28] } \\
\text { (adults) }\end{array}$ & India & 200 & $57 \%$ & $43 \%$ \\
\hline Koops et al. [13] (adults) & Germany & 604 & $79.1 \%$ & $20.9 \%$ \\
\hline
\end{tabular}

from the CeT. The CHA bifurcates into gastroduodenal artery and proper hepatic artery which divides into right hepatic artery and left hepatic artery. It is very important to understand the variant anatomy of these arteries for safe liver transplantation, traumatic vascular injury repair and abdominal tumour surgery in children as much as in adults [3].

Although digital subtraction angiography is regarded as the gold standard imaging method in the evaluation of abdominal vascular structures, MDCT angiography is cheaper, easily accessible, safer and particularly noninvasive when compared to digital subtraction angiography. MDCT angiography has become a widely used imaging method which provides highly accurate results and has gained acceptance in the identification of vascular anatomy $[2,24]$. Magnetic resonance angiography is another useful method used to define the anatomy of the abdominal vascular structure in children. The greatest advantage is that it does not use ionizing radiation.

Panagouli et al. [21] published a systematic review about CeT variations including a total of 36 studies with 12,196 Japanese, Korean, Caucasian and Indian individuals from different countries [4, $10,18,22]$. The CeT was trifurcated into the three basic branches of the classical anatomy in $89.42 \%$ of cases. They mentioned different forms of bifurcation were recorded in 19 out of the 36 articles. Bifurcation of $\mathrm{CeT}$ as hepatosplenic trunk with the left gastric artery arising from the aorta was the most common (7.4\%) variation. Absence of the CeT was the rarest variation $(0.38 \%)$. In the present study, a total of $157(90.2 \%)$ of the 174 Turkish children had normal CeT anatomy similar to cases from other countries including adults (Table 5). 'Hepatosplenic trunk + left gastric artery + superior mesenteric artery' was the most common variation (4\%) which confirmed data reported by most authors. 'Absence of the CeT' was not seen in this study.

Common hepatic artery variations were reported in a wide range by Gumus et al. [9] from Turkey (33.2\%), Song et al. [25] from Korea (42\%), Sureka et al. [27] from India (20.4\%), Tharangarajah et al. [28] from South India (43\%), Bertevello et al. [1] from Brazil (31.7\%), and Koops et al. [13] from Germany (20.9\%). Song et al. [25] completed the widest study including non-reported variations and new classifications in 5002 patients. In the current study, children had high $\mathrm{CHA}$ variation rate $(35.6 \%)$ like the literature involving adults from different countries. Contrary to divergent populations from various roots, Gumus et al. [9] from Turkey reported a study comprising 820 adults with a relatively approximate ethnicity to the present study. According to their findings, CHA variations were found in $33.2 \%$. Similarly, our findings support the idea that CHA variations are common in children not only compared to older patients from different races, but also to adults with the same ethnicity. The most common variation in this study is 'replaced left hepatic artery originating from left gastric artery' (type 2) which is similar to the studies given in Table 6. It is also mentioned in textbooks that the origin of 
left hepatic artery is usually from the branch of the CeT (most frequently from the left gastric artery) [11].

latrogenic arterial injuries include pseudoaneurysm, extravasation, arteriovenous fistula, arteriobiliary fistula, and dissection. Onizuka et al. [20] reported that arterial injuries occurred in 38 of 906 cases during transcatheter arterial chemoembolisation for hepatocellular carcinoma. They mentioned that iatrogenic arterial injuries frequently occurred in the extrahepatic artery or replaced hepatic artery. In addition, Catalano et al. [3] published that ' $\mathrm{CHA}$ trifurcation into the right hepatic artery, left hepatic artery and gastroduodenal artery' can cause gastric or duodenal hypoperfusion due to clamping or ligation of the CHA. They also postulated that 'replaced or accessory left hepatic artery' increases complexity of the surgery. If paediatric surgeons or other clinicians are aware and take care of CHA variations, children can avoid iatrogenic surgical injuries. It is important to be aware of $\mathrm{CeT}$ and $\mathrm{CHA}$ variations in children to increase their life span.

A potential limitation of our study is the relatively small number of cases involved and the retrospective design. The reason of the small number of cases is that MDCT angiography rarely is used in children because of the high ionising-radiation exposure. Another limitation is that the present study included some children with MDCT angiography images before liver transplantation. It was different from bias of patients' selection compared to the previous adult studies. It may be more accurate to make comparisons of completely healthy children with adults. Since optimal timing for arterial and/or venous phase MDCT images was not always possible to obtain in every paediatric cases, three-dimensional reconstruction images could not be collected for all of the cohort enrolled and diagnosis were basically made with source images which is another limitation in the current study. Due to the small vessel lumen diameter, as expected in paediatric population, optimal imaging was not obtained.

\section{CONCLUSIONS}

The prevalences of CeT and hepatic artery variations are high in children, as they are in older patients. Awareness of these variations by paediatric surgeons is important in terms of avoiding iatrogenic injury and in promoting surgical procedure planning for liver transplantation and abdominal tumour surgery.

\section{Acknowledgements}

We would acknowledge Mr. Burak Polat in assisting to review the publications and Ms. Yeliz Pekcevik for her assistance in the online literature search.

\section{REFERENCES}

1. Bertevello PL, Chaib E. [Hepatic artery system variations correlated to split-liver surgery: anatomic study in cadavers]. Arq Gastroenterol. 2002; 39(2): 81-85, doi: 10.1590/S0004-28032002000200003, indexed in Pubmed: 12612710.

2. Boraschi P, Donati F, Rossi M, et al. Role of MDCT in the detection of early abdominal complications after orthotopic liver transplantation. Clin Imaging. 2016; 40(6): 1200-1206, doi: 10.1016/j.clinimag.2016.08.018, indexed in Pubmed: 27616153.

3. Catalano OA, Singh $\mathrm{AH}$, Uppot RN, et al. Vascular and biliary variants in the liver: implications for liver surgery. Radiographics. 2008; 28(2): 359-378, doi: 10.1148/ rg.282075099, indexed in Pubmed: 18349445.

4. Chen H, Yano R, Emura $\mathrm{S}$, et al. Anatomic variation of the celiac trunk with special reference to hepatic artery patterns. Ann Anat. 2009; 191(4): 399-407, doi: 10.1016/j. aanat.2009.05.002, indexed in Pubmed: 19540742.

5. Clemente CD. Gray's anatomy. 30th ed. Philadelphia, Pa: Lea \& Febiger. 1984.

6. Covey AM, Brody LA, Maluccio MA, et al. Variant hepatic arterial anatomy revisited: digital subtraction angiography performed in 600 patients. Radiology. 2002; 224(2): 542-547, doi: 10.1148/radiol.2242011283, indexed in Pubmed: 12147854.

7. Farghadani M, Momeni M, Hekmatnia A, et al. Anatomical variation of celiac axis, superior mesenteric artery, and hepatic artery: Evaluation with multidetector computed tomography angiography. J Res Med Sci. 2016; 21: 129, doi: 10.4103/1735-1995.196611, indexed in Pubmed: 28331515.

8. Gielecki J, Zurada A, Sonpal N, et al. The clinical relevance of coeliac trunk variations. Folia Morphol. 2005; 64(3): 123-129, indexed in Pubmed: 16228946.

9. Gümüs $H$, Bükte $Y$, Özdemir $E$, et al. Variations of the celiac trunk and hepatic arteries: a study with 64-detector computed tomographic angiography. Eur Rev Med Pharmacol Sci. 2013; 17(12): 1636-1641, indexed in Pubmed: 23832731.

10. Hiatt JR, Gabbay J, Busuttil RW. Surgical anatomy of the hepatic arteries in 1000 cases. Ann Surg. 1994; 220(1): 50-52, indexed in Pubmed: 8024358.

11. Hollinshead WH. The thorax, abdomen and pelvis. In: Anatomy for Surgeons, Vol. 2. New York: Harper \& Row Publishers. 1971: 346.

12. Iezzi R, Cotroneo AR, Giancristofaro D, et al. Multidetector-row CT angiographic imaging of the celiac trunk: anatomy and normal variants. Surg Radiol Anat. 2008; 30(4): 303-310, doi: 10.1007/s00276-008-0324-7, indexed in Pubmed: 18286222.

13. Koops A, Wojciechowski B, Broering DC, et al. Anatomic variations of the hepatic arteries in 604 selective celiac and superior mesenteric angiographies. Surg Radiol Anat. 
2004; 26(3): 239-244, doi: 10.1007/s00276-004-0229-z, indexed in Pubmed: 14968265.

14. Lipshutz B. A composite study of the coeliac axis artery. Ann Surg. 1917; 65(2): 159-169, indexed in Pubmed: 17863663.

15. Marco-Clement I, Martinez-Barco A, Ahumada N, et al. Anatomical variations of the celiac trunk: cadaveric and radiological study. Surg Radiol Anat. 2016; 38(4): 501-510, doi: 10.1007/s00276-015-1542-4, indexed in Pubmed: 26267305.

16. Michel NA. Blood supply and anatomy of the upper abdominal organs with a descriptive atlas. Lippincott, Philadelphia. 1955: 64-69.

17. Natsis K, Piagkou M, Stamatopoulos T, et al. Anastomotic loop between common hepatic artery and gastroduodenal artery in coexistence with an aberrant right hepatic artery. Folia Morphol. 2017 [Epub ahead of print], doi: 10.5603/ FM.a2017.0023, indexed in Pubmed: 28281726.

18. Natsume T, Shuto K, Yanagawa N, et al. The classification of anatomic variations in the perigastric vessels by dual-phase $C T$ to reduce intraoperative bleeding during laparoscopic gastrectomy. Surg Endosc. 2011; 25(5): 1420-1424, doi: 10.1007/ s00464-010-1407-1, indexed in Pubmed: 20976496.

19. Olewnik $\measuredangle$, Wysiadecki G, Polguj M, et al. Types of coeliac trunk branching including accessory hepatic arteries: a new point of view based on cadaveric study. Folia Morphol. 2017 [Epub ahead of print], doi: 10.5603/ FM.a2017.0053, indexed in Pubmed: 28612916.

20. Onizuka $H$, Sueyoshi $E$, Ishimaru $H$, et al. Arterial injury during transcatheter arterial chemoembolization for hepatocellular carcinoma: predictors of risk and outcome. Abdom Radiol (NY). 2017; 42(10): 2544-2550, doi: 10.1007/ s00261-017-1168-6, indexed in Pubmed: 28493072.
21. Panagouli $E$, Venieratos $D$, Lolis $E$, et al. Variations in the anatomy of the celiac trunk: A systematic review and clinical implications. Ann Anat. 2013; 195(6): 501-511, doi: 10.1016/j.aanat.2013.06.003, indexed in Pubmed: 23972701.

22. Prakash, Rajini T, Mokhasi V, et al. Coeliac trunk and its branches: anatomical variations and clinical implications. Singapore Med J. 2012; 53(5): 329-331, indexed in Pubmed: 22584973.

23. Raikos A, Pynadath N, Anguswamy N, et al. Ring-shaped variation of the coeliac trunk branches. Folia Morphol. 2015; 74(4): 540-543, doi: 10.5603/FM.2015.0120, indexed in Pubmed: 26620519.

24. Savastano S, Teso S, Corrà S, et al. Multislice CT angiography of the celiac and superior mesenteric arteries: comparison with arteriographic findings. Radiol Med. 2002; 103(5-6): 456-463, indexed in Pubmed: 12207181.

25. Song SY, Chung JW, Yin YHu, et al. Celiac axis and common hepatic artery variations in 5002 patients: systematic analysis with spiral CT and DSA. Radiology. 2010; 255(1): 278-288, doi: 10.1148/radiol.09090389, indexed in Pubmed: 20308464.

26. Standring S. Gray's Anatomy. 40th Ed. Churchill Livingstone Elsevier. London, 2008; 1073-1074.

27. Sureka B, Mittal MK, Mittal A, et al. Variations of celiac axis, common hepatic artery and its branches in 600 patients. Indian J Radiol Imaging. 2013; 23(3): 223-233, doi: 10.4103/0971-3026.120273, indexed in Pubmed: 24347852.

28. Thangarajah A, Parthasarathy R. Celiac axis, common hepatic and hepatic artery variants as evidenced on MDCT angiography in south indian population. J Clin Diagn Res. 2016; 10(1): TC01-TC05, doi: 10.7860/ JCDR/2016/17045.7105, indexed in Pubmed: 26894140. 